\title{
Perceived effects of coloured overlays on reading material in persons with albinism
}

\author{
NT Makgaba* and OA Oduntan $\uparrow$
}

* Department of Optometry, University of Limpopo, P Bag X1106 Sovenga, 0727 South Africa

†Department of Optometry, University of KwaZulu Natal, P Bag X54001, Durban, 4001 South

Africa

$*<$ mtn@702mail.co.za $>$

$\uparrow<$ oduntanoa@ukzn.ac.za $>$

Received 3 June 2008; revised version accepted 30 September 2008

\section{Abstract}

Persons with albinism often complain of glare when reading. They may therefore benefit from coloured filter overlays just as they benefit from tinted lenses. The purpose of this study was to assess the effect of coloured overlays on print perception in persons with oculocutaneous albinism (OCA). Fifty subjects were included in this study, their ages ranged from 12 to 31 years with a mean of 16.12 years ( $\mathrm{SD}= \pm 4.56$ years). Following refraction and subsequent compensation for refractive errors, subjective perception of print was examined with the subject looking at the Wilkins ${ }^{\circledR}$ reading rate test chart with and without colored filter overlay/s. The subjects were asked to respond to questions previously used in a questionnaire by Wilkins (2001). The percentage frequencies of positive (beneficial) responses were used to decide whether or not a particular overlay would enhance reading performance. McNemar's test was used to establish significant differences between responses to questions without and with overlays. All single overlays gave greater percentages of positive responses (92.0-
$97.2 \%)$ than without overlay $(85.2 \%)$. The single overlay that provided the highest positive responses was blue (97.2\%) and the least was purple (92.0\%). All double overlays, except grey/grey (82.0\%) gave greater positive responses than without overlay $(85.2 \%)$. Aqua/blue gave the greatest positive responses (possible benefits) $(97.2 \%)$, followed by rose/rose $(96.8 \%)$. Comparing the responses without overlay with single and double overlays, the difference in responses to the five questions was only significant $(p<0.05)$ with regard to brightness of the surface. The results suggest that overlays provided a more glare-free reading surface than without an overlay. It was, therefore concluded that the best advantage of the coloured overlays was in glare reduction. Although this study showed that there were more subjects who preferred single blue and aqua/blue double overlays, inter-subject preference for overlays varied, therefore the best overlay should be established for every patient for whom overlay is to be prescribed.

Key words: Oculocutaneous albinism, Coloured overlays, Glare, Filter overlays and Reading. 


\section{Introduction}

Albinism is a congenitally inherited condition of hypomelanosis involving the pigmented structures of the body, namely the eyes, skin and hair. In ocular albinism (OA) only the eyes are affected, whereas in oculocutaneous albinism (OCA) there is a lack of pigmentation in the eyes, hair and skin ${ }^{1}$. Oculocutaneous albinism type 2 (OCA2) is the predominant type of OCA found throughout the sub-Saharan Africa; with a classic phenotype among the black population being sandy to yellow hair, pale chalky coloured skin and blue to hazel eyes ${ }^{2}$. In Zimbabwe, a prevalence of 1 in 4182 was reported among school children ${ }^{3}$, with a higher frequency of 1 in 1000 among the isolated Tonga people 4 . In South Africa, in Soweto, south west of Johannesburg, the frequency was 1 in 3900 and was partly attributed to the practice of consanguineous marriages among certain ethnic groups ${ }^{5}$. The frequency of OCA2 in the rural area of the Limpopo Province of South Africa, where this study was conducted, is particularly high, at 1 in 1500 neonates $^{6}$.

Tinted lenses are used by eye care practitioners to assist people with low vision to maximize the use of residual vision, improve visual function, control glare and improve orientation and mobility skills ${ }^{7}$. They are often prescribed to people with various ocular diseases including age-related macular degeneration (AMD), retinitis pigmentosa (RP), cataract, diabetic retinopathy, cone dystrophy and oculocutaneous albinism ${ }^{7}$. The ability of yellow filter lenses to improve vision has been documented ${ }^{8-13}$. Other colours such as orange, red and grey also have the potential to enhance vision ${ }^{9,10}$. Due to hypopigmentation of the iris and the retinal pigment epithelium, high level of sensitivity to glare is a major symptom among persons with albinism. Coloured ophthalmic filters are often prescribed for people with albinism to reduce ocular discomfort, enhance visual performance or both ${ }^{14}$. Dark amber lenses significantly decrease the light intensity and are able to diminish all visual adverse effects in people with albinism ${ }^{15}$. The ability of coloured short wavelength light-absorbing filters to improved contrast sensitivity among subjects has been attributed to reduction in intraocular light scatter ${ }^{8,16}$.

It has been recognized that coloured plastic overlays improve reading fluency and speed in certain individuals with reading difficulties ${ }^{17-28}$. In addition to improving reading fluency, they also reduce symptoms of asthenopia ${ }^{13}$. The intuitive colored plastic overlays ${ }^{\circledR}$ developed by Wilkins ${ }^{18}$ consist of 10
A5-sized plastic sheets with the following colours: rose, pink, purple, aqua, blue, lime-green, mint-green, yellow, orange and grey. They are distributed by IOO Marketing Ltd, London, UK. The colours are based on the CIE 1976 hue saturated value (HSV) colour space, where hue angle $h u v$ and saturation suv are used to specify colours in an orderly and scientific manner ${ }^{18}$. The hue angle between neighboring colours averages 40 degrees with a standard deviation (SD) of 7.7 degrees, the saturation averages 0.52 (SD $=0.19)^{18}$.

In view of extreme glare sensitivity experienced by individuals with albinism, we felt that coloured filter overlays could provide a significant glare relief to them. The purpose of this study, therefore was to investigate the possible benefits of various coloured filter overlays on reading in persons with oculocutaneous albinism, which hitherto has not been investigated.

\section{Methods}

The proposal to conduct this study was approved by the Research and Ethics Committees of the University of Limpopo, South Africa. Fifty subjects (28 males and 22 females) with oculocutaneous albinism were included in this study. Their ages ranged from 12 to 31 years with a mean of 16.12 years $(\mathrm{SD}= \pm 4.56$ years). The subjects were university students, high school and primary school learners. The high school and primary school participants were boarding learners at the special schools for the disabled children in the Limpopo Province. A detailed explanation of the research procedure was presented to each subject. In addition, the participants were assured that no discomfort or injury could result from the procedure. All the university subjects who participated in the study signed a written consent form and the principals of the primary and high school subjects signed the form on behalf of the parents of the children.

The Wilkins reading rate test chart $^{24}$ and the intuitive coloured filter overlays ${ }^{18}$ were used in this study. Following refractive error measurement and refractive compensation, each subject was seated at a table that was illuminated by the general overhead room source provided by fluorescent lamps. The illumination levels were not measured because light meter was not available; however, approximately the same level of illumination was used for each subject for the procedures with and without overlay/s. Each subject was asked to look at words on the Wilkins 
reading rate test chart without coloured overlay, and subsequently through each single overlay, followed by double overlays. They were then asked to respond to the questions previously asked by Wilkins on their symptoms questionnaire ${ }^{24}$.

The colours of overlays used in the study and their percentages transmission values were mint green $(85 \%)$, pink $(78 \%)$, aqua $(81 \%)$, blue $(74 \%)$, rose $(78 \%)$, lime-green $(86 \%)$, purple $(67 \%)$, orange $(83 \%)$, grey $(71 \%)$, yellow (93\%)18. These single overlays were combined to form double overlays as pink/pink, aqua/blue, orange/yellow, rose/rose, yellow/lime-green, pink/rose, mint-green/aqua, rose/orange, blue/blue, yellow/yellow, mint/mint, orange/ orange, lime-green/mint-green, purple/pink, limegreen/lime-green, blue/purple, aqua/aqua, purple/ purple and grey/grey. The overlays were randomly presented to the subjects during the study.

With the subjects looking at the rate of reading test chart with or without the overlays, the following questions were asked: 1. "Do the letters appear still or moving?" 2. "Are the letters appearing clear or blurred?" 3. "Are the words too close to one another or far enough apart?" 4. "Is the page too bright, not bright enough or just about right"? 5. "Does the page hurt your eyes to look at or it is just about right?" In the analysis of responses, those in bold were referred to as positive, and those in italics were considered to be negative. The descriptive statistics of the Statistical Package for Social Science (SPSS) software and McNemar's test were used to analyze the data. In order to rank the overlays according to their benefits, the positive responses for each overlay were added together to obtain the total number of positive responses for each overlay. Similarly, the negative responses were added together to obtain the value of negative for each overlay. The overlay with the highest positive responses was considered to be of greatest benefits for the subjects. Significant difference between responses to the questions asked without overlay and with the best single and double overlay was examined with the McNemar's test.

\section{Results}

The percentage of positive responses without overlay was $85.2 \%$. The percentage frequency of the positive responses for all the single overlays was better than without overlays (see Tables 1 and 2 and Figure $1)$.
Table 1. Showing the Wilkinson ${ }^{18}$ questions 1-5 and the positive responses with the single overlays for all subjects $(\mathrm{N}=50)$. Blue overlay provided the highest number of positive responses and purple has the least. The highest score per question would be 50 and 250 for the five questions in this forced-choice procedure

\begin{tabular}{|l|c|c|c|c|c|c|}
\hline \multirow{2}{*}{$\begin{array}{l}\text { Overlay } \\
\text { colours }\end{array}$} & \multicolumn{5}{|c|}{ Questions 1- 5 and positive responses } \\
\cline { 2 - 7 } & Still & Clear & $\begin{array}{c}\text { Far } \\
\text { enough }\end{array}$ & $\begin{array}{c}\text { Just } \\
\text { about } \\
\text { right }\end{array}$ & $\begin{array}{c}\text { Does } \\
\text { not } \\
\text { hurt }\end{array}$ & Total \\
\hline Blue & 50 & 48 & 49 & 47 & 49 & 243 \\
\hline Mint green & 50 & 46 & 49 & 45 & 49 & 239 \\
\hline Lime green & 49 & 49 & 49 & 43 & 48 & 238 \\
\hline Rose & 50 & 47 & 48 & 43 & 50 & 238 \\
\hline Orange & 49 & 47 & 50 & 44 & 47 & 237 \\
\hline Pink & 49 & 45 & 47 & 45 & 47 & 233 \\
\hline Grey & 49 & 49 & 49 & 36 & 49 & 232 \\
\hline Yellow & 49 & 46 & 47 & 41 & 48 & 231 \\
\hline Aqua & 48 & 45 & 48 & 41 & 48 & 230 \\
\hline Purple & 47 & 47 & 48 & 40 & 48 & 230 \\
\hline Range & $47-50$ & $45-49$ & $47-50$ & $36-47$ & $47-50$ & $230-$ \\
\hline Mean & 49 & 46.9 & 48.4 & 42.5 & 48.3 & 235.1 \\
\hline SD & 0.94 & 1.45 & 0.97 & 3.14 & 0.95 & 4.48 \\
\hline $\begin{array}{l}\text { No Over- } \\
\text { lay }\end{array}$ & 48 & 45 & 45 & 29 & 46 & 213 \\
\hline
\end{tabular}

Table 2. The total and percentage, minimum, maximum, mean and standard deviation of the positive responses $(\mathrm{N}=50)$ for the single overlays, for the five questions asked. The values are presented in order of decreasing total frequency.

\begin{tabular}{|l|c|c|c|c|c|}
\hline \multirow{2}{*}{$\begin{array}{l}\text { Overlay } \\
\text { colours }\end{array}$} & \multicolumn{5}{|c|}{ Questions 1- 5 and positive responses } \\
\cline { 2 - 6 } & Total (\%) & MIN & MAX & MEAN & SD \\
\hline Blue & $243(97.2)$ & 47 & 50 & 48.6 & 1.12 \\
\hline $\begin{array}{l}\text { Lime } \\
\text { green }\end{array}$ & $239(95.6)$ & 45 & 50 & 47.8 & 2.17 \\
\hline $\begin{array}{l}\text { Mint } \\
\text { green }\end{array}$ & $238(95.2)$ & 43 & 49 & 4706 & 2.61 \\
\hline Rose & $238(95.2)$ & 43 & 50 & 47.6 & 2.90 \\
\hline Orange & $237(94.8)$ & 44 & 50 & 47.4 & 2.30 \\
\hline Pink & $233(93.2)$ & 45 & 49 & 46.6 & 1.67 \\
\hline Grey & $232(92.8)$ & 36 & 49 & 46.4 & 5.81 \\
\hline Yellow & $231(92.4)$ & 41 & 49 & 46.2 & 3.11 \\
\hline Aqua & $230(92.0)$ & 41 & 48 & 46.0 & 3.08 \\
\hline Purple & $230(92.0)$ & 40 & 48 & 46.0 & 3.39 \\
\hline $\begin{array}{l}\text { No } \\
\text { Overlay }\end{array}$ & $213(85.2)$ & 29 & 48 & 42.6 & 7.70 \\
\hline
\end{tabular}


The single blue overlay yielded the highest positive responses $(97.2 \%)$, followed by mint green with $95.6 \%$. Purple yielded the lowest percentage, $(92.0 \%)$. The percentage of negative responses for "without overlay' was $14.8 \%$. The single overlay with the least negative response was blue (2.8\%) and those with the highest value ( $8 \%$ each) were purple and aqua.

Double overlays were also found to yield greater positive responses than without overlays (see Tables 3, 4 and Figure 1). However, the difference was significant only in the brightness of the reading surface.

Table 3. Showing the Wilkins ${ }^{18}$ questions 1-5 and the positive responses with double overlays for all subjects $(\mathrm{N}=50)$. Aqua/blue overlay provided the highest number of positive responses and grey/grey provided the least number of positive responses. The highest score per question would be 50 and 250 for the five questions in this forced-choice procedure.

\begin{tabular}{|c|c|c|c|c|c|c|}
\hline \multirow{2}{*}{$\begin{array}{l}\text { Overlay } \\
\text { colours }\end{array}$} & \multicolumn{6}{|c|}{ Questions 1-5 and positive responses } \\
\hline & Still & Clear & $\begin{array}{l}\text { Far } \\
\text { enough }\end{array}$ & $\begin{array}{l}\text { Just } \\
\text { about right }\end{array}$ & $\begin{array}{l}\text { Does not } \\
\text { hurt }\end{array}$ & Total \\
\hline Aqua/blue & 50 & 46 & 50 & 50 & 49 & 243 \\
\hline Rose/rose & 49 & 49 & 50 & 50 & 48 & 242 \\
\hline M.gre/m. green & 50 & 47 & 50 & 50 & 48 & 241 \\
\hline Pink/pink & 49 & 48 & 50 & 50 & 49 & 240 \\
\hline L/green/l. green & 50 & 49 & 50 & 50 & 48 & 240 \\
\hline Rose/orange & 49 & 49 & 49 & 49 & 48 & 239 \\
\hline M.green/aqua & 49 & 47 & 48 & 48 & 49 & 239 \\
\hline L.gre/m. green & 48 & 47 & 50 & 50 & 48 & 236 \\
\hline Pink/rose & 46 & 46 & 49 & 49 & 48 & 236 \\
\hline Orange/orange & 48 & 45 & 50 & 50 & 48 & 234 \\
\hline Blue/blue & 49 & 48 & 49 & 49 & 48 & 233 \\
\hline Aqua/aqua & 47 & 47 & 50 & 50 & 47 & 232 \\
\hline Orange/yellow & 47 & 43 & 50 & 50 & 49 & 231 \\
\hline Yellow/l. green & 48 & 44 & 50 & 50 & 46 & 227 \\
\hline Purple/pink & 50 & 47 & 49 & 499 & 47 & 226 \\
\hline Blue/purple & 50 & 47 & 50 & 50 & 47 & 224 \\
\hline Yellow/yellow & 47 & 39 & 50 & 50 & 45 & 217 \\
\hline Purple/purple & 50 & 47 & 48 & 48 & 45 & 215 \\
\hline Grey/grey & 49 & 47 & 48 & 48 & 48 & 205 \\
\hline Range & $46-50$ & $39-49$ & $48-50$ & $48-50$ & $45-49$ & \begin{tabular}{|l|}
$205-$ \\
243 \\
\end{tabular} \\
\hline Mean & 48.7 & 46.4 & 49.5 & 49.5 & 47.6 & 231.6 \\
\hline $\mathrm{SD}$ & 1.25 & 2.39 & 0.77 & 0.77 & 1.21 & 10.36 \\
\hline No overlay & 48 & 45 & 45 & 45 & 46 & 213 \\
\hline
\end{tabular}


Table 4. The total and percentage, minimum, maximum, mean and standard deviation of the positive responses by the 50 subjects for the double overlays, for the five questions asked. The values are presented in order of decreasing total frequency.

\begin{tabular}{|l|l|l|l|l|l|}
\hline \multirow{2}{*}{$\begin{array}{l}\text { Overlay } \\
\text { colours }\end{array}$} & \multicolumn{2}{|c}{ Frequencies of positive responses } & \multicolumn{2}{l|}{} \\
\cline { 2 - 6 } & Total (\%) & Min & Max & Mean & SD \\
\hline Aqua/blue & $243(97.2)$ & 46 & 50 & 48.6 & 1.67 \\
\hline Rose/rose & $242(96.8)$ & 46 & 50 & 48.4 & 1.52 \\
\hline M.gre/m. green & $241(96.4)$ & 46 & 50 & 48.2 & 1.79 \\
\hline Pink/pink & $240(96.0)$ & 44 & 50 & 48.0 & 2.35 \\
\hline L/greem/l. green & $240(96.0)$ & 43 & 50 & 48.0 & 2.92 \\
\hline Rose/orange & $239(95.6)$ & 44 & 49 & 47.8 & 2.17 \\
\hline M.green/aqua & $239(95.6)$ & 46 & 49 & 47.8 & 1.30 \\
\hline L.gre/m. green & $236(94.4)$ & 43 & 50 & 47.2 & 2.59 \\
\hline Pink/rose & $236(94.4)$ & 46 & 49 & 47.5 & 1.30 \\
\hline Orange/orange & $234(93.6)$ & 43 & 50 & 46.8 & 2.77 \\
\hline Blue/blue & $233(93.2)$ & 39 & 49 & 46.6 & 4.28 \\
\hline Aqua/aqua & $232(92.8)$ & 41 & 50 & 46.4 & 3.29 \\
\hline Orange/yellow & $231(92.4)$ & 42 & 50 & 46.2 & 3.56 \\
\hline Yellow/l. green & $227(90.8)$ & 39 & 50 & 15.2 & 4.22 \\
\hline Purple/pink & $226(90.4)$ & 33 & 50 & 44.8 & 6.94 \\
\hline Blue/purple & $224(89.6)$ & 30 & 50 & 43.4 & 8.41 \\
\hline Yellow/yellow & $217(86.8)$ & 36 & 40 & 43.0 & 5.77 \\
\hline Purple/purple & $215(86.0)$ & 25 & 50 & 41.0 & 10.2 \\
\hline No overlay & $213(85.2)$ & 29 & 48 & 42.6 & 7.7 \\
\hline Grey/grey & $205(82.0)$ & 13 & 49 & 42.6 & 15.7 \\
\hline
\end{tabular}

The highest percentage of positive responses was with aqua/blue) $(97.2 \%$ ) followed by $96.8 \%$ for rose/ rose (Tables 3 and 4). Grey/grey (82.0\%) was the only double overlay with less value than without an overlay. The double overlay with the least negative response was aqua/blue $(2.8 \%)$ and that with the highest value (18\%) was grey/grey. Figure 1 shows the frequency of positive responses for the best double overlay (aqua/blue), best single overlay (blue) and no overlay, for the five questions asked. The responses for the single and double overlays were higher than without overlay in all cases.

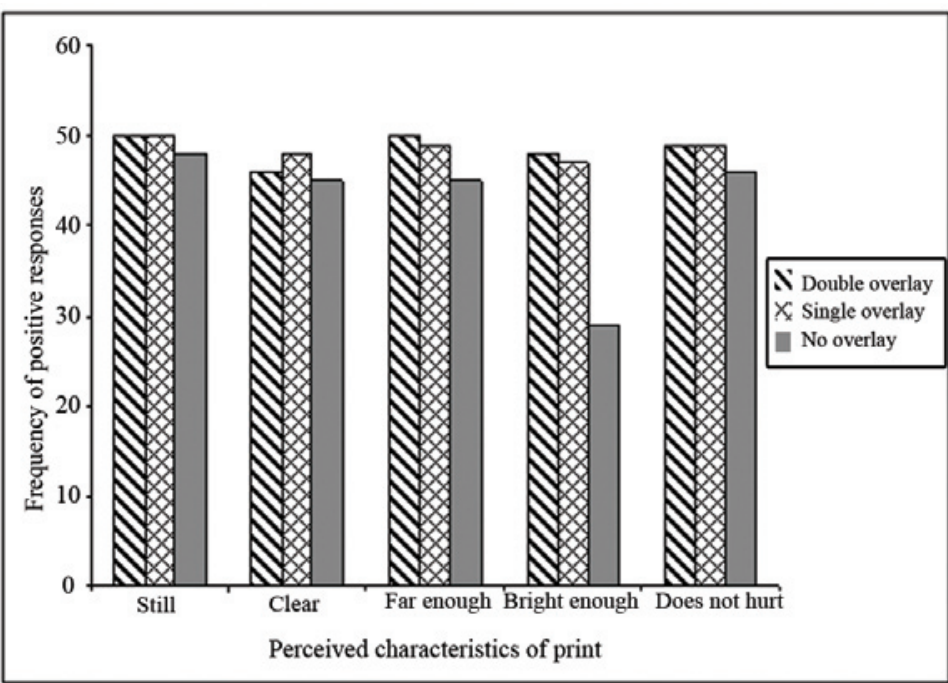

Figure 1. Showing the frequency of the responses to each question through the best double overlays (Aqua/blue), best single overlay (blue) and no overlay. Both best overlays yielded greater positive responses for all the five questions than without an overlay. 
There was a significant difference in the responses between the perceived print characteristics through the overlays compared to without overlays with regard to brightness of the page $(p<0.05)$. Most of the subjects found the page without overlay to be too bright. The differences found with the other questions, however, were not statistically significant for with and without overlays.

\section{Discussion and Conclusion}

Coloured lenses and overlays are known to improve quality of vision ${ }^{7-28}$. Even children with normal vision could benefit from reading with overlays. Tyrell et al..$^{20}$ found that more children with normal vision reported symptoms of visual discomfort when reading without overlays than when reading with overlays. Our results show that individuals with albinism will benefit from overlays because the subjects reported more positive responses (Tables 1-4 and Figure 1), hence less negative responses when viewing print with overlays compared to when viewing without overlays. It is assumed that all the single overlays and most doubles, except a few ones such as grey/grey would provide some benefits for reading to individuals with albinism, especially in terms of visual comfort. Although positive responses to all single and all double overlays except grey/grey were generally higher than without overlay, the $\mathrm{McNe}$ mar's test which was used to establish the differences in responses without and with the best single and double overlays showed that the differences were only significant $(p>0.05)$ with regard to the brightness of the surface. This suggests that the best benefit of the overlay was in the reduction of glare effect for the subject. This may explain the subjective comments by the subjects that the overlays were more comfortable than reading without overlay.

There are two characteristics of the coloured filter overlays which may influence vision; these are the colour (hue) and the transmission value. It has been reported that short wavelength-absorbing lenses such as yellow improve print contrast, therefore improving the print appearance by reducing intraocular light scattering 8,16 . In the present study, the colours and their transmission values which have the potential to provide the greatest benefits for reading among the single overlays were blue (74\%), mint green $(85 \%)$ and lime green $(86 \%)$. The overlay preference may presumably be attributed to both the transmission values and colours of the overlays, as there was no con- sistent relationship between overlay preference and transmission values. The obvious finding, however, was that vision with overlays was perceived to be better than without overlays.

Among the double overlays, aqua/blue provided the greatest positive responses, suggesting greatest potential for benefits. Again, this could be attributed to both hue and transmission percentages of the overlays. The grey/grey combination was the only overlay that was considered not to be of benefit to the subjects, as the percentage of positive responses (benefits) $(82.0 \%)$ was lower than without overlay $(85.2 \%)$. The poor responses with the grey/grey overlays may be attributed to the dim nature of the combined overlays. This may relate to the low transmission value $(71 \%)$; the combination of which may yield even lower transmission value. This suggests that, although individuals with albinism prefer dim surfaces when reading, there is an optimal transmission percentages preferred by these people and when the surface brightness becomes too low, it is detrimental to their vision.

It is concluded that coloured overlays will be of benefit for reading in persons with oculocutaneous albinism. This is in agreement with previous findings that coloured overlays can reduce symptoms of visual stress and improve reading speed and therefore, enhance reading performance ${ }^{18-28}$. However, it should be noted that in the case of individuals with albinism, the effect is more of preventing glare rather than having effects on the clearness or stability of the prints. This implied that although filter overlays may have various benefits for individual with albinism, the main benefit is in reducing glare, hence providing comfort. It is recommended that the test for coloured filter overlays for reading should be part of routine eye examination for patients with albinism. The overlay may reduce the glare experienced from the material being read. In view of the variability in the overlay preference, Optometrists should determine and prescribe the appropriate overlay for each person with albinism. As most children with albinism attend special education schools. It is further recommended that, the Department of Education should consider supplying coloured overlays for children with albinism in those schools.

\section{Acknowledgement}

Assistance of Mrs. Fikile Nkwanyana in data analysis is acknowledged. Thanks to all subjects who participated in the study. 


\section{References}

1. Oetting WS, Brilliant M, King RA. The clinical spectrum of albinism in humans. Mol Med Today 19962 330-335.

2. Lund PM. Oculocutaneous albinism in Southern Africa: Population structure, health and genetic care. Ann Hum Biol 200532 168-173.

3. Lund PM. Distribution of oculocutaneous albinism in Zimbabwe. J Med Genet 199633 641-644.

4. Lund PM, Puri N, Durham-Pierre D, King RA, Brilliant $\mathrm{MH}$. Ocuolcutaneous albinism in an isolated Tonga community in Zimbabwe. J Med Genet 1997 34, 733-735.

5. Kromberg JG, Jenkins T. Prevalence of albinism in the South African Negros. S Afr Med J 198261 383-386.

6. Venter PA, Christianson AL, Hutamo CL, Makhura MP, Gericke GS. Congenital anomalies in rural black South African neonates - a silent epidemic. S Afr Med J 199585 15-20.

7. Eperjesi F, Fowler CW, Evans BJW. Do tinted lenses or filters improve visual performance in low vision? A review of the literature. Ophthal Physiol Opt 200222 68-77.

8. Wolffsohn JS, Cochrane AL, Khoo H, Yoshimitsu Y, Wu S. Contrast is enhanced by yellow lenses because of selective reduction of short wavelength light. Optom Vis Sci 2000 77 73-81.

9. Wolffsohn JS, Dinardo C, Vingrys AJ. Benefit of coloured lenses for age-related macular degeneration. Ophthal Physiol Opt 200222 300-311.

10. de Fez MD, Luque MJ, Vigueira V. Enhancement of contrast sensitivity and losses of discrimination with tinted lenses. Optom Vis Sci 200279 590-597.

11. Pérez MJ, Puell MC, Sánchez C, Langa A. Effect of a yellow filter on mesopic contrast perception and differential light sensitivity in the visual field. Ophthal Res $20033554-$ 59.

12. Pérez-Carrasco MJ, Puell MC, Sánchez-Ramos C, LópezCatro A, Langa A. Effect of a yellow filter on contrast sensitivity and disability glare after laser in situ keratomileusis under mesopic and photopic conditions. J Refract Surg 200521 158-165.

13. Valentincic NV, Berendschot TT, Hawlina M, Kraut A, Rothova A. Effect of tinted optical filters on visual acuity and contrast sensitivity in patients with inflammatory cystoid macular edema. Retina 200727 483-489.

14. Provines WF, Harvile B, Block M. Effects of yellow optical filters on contrast sensitivity function of albino patients. $J$ Am Optom Assoc 199768 353-359.

15. Rosenblum YZ, Zak PP, Ostrovsky MA, Smolyaninova IL, Bora EV, Dyadina UV Trovimova NN, Aliyev AGD. Spectral filters in low vision correction. Ophthal Physiol Opt. 200020 335-341.

16. Zigman S. Vision enhancement using a short wave-length light-absorbing filter. Optom Vis Sci 199067 100-104.

17. Saint-John L, White MA. The effect of coloured transparencies on the reading performance for reading disability. $\mathrm{J} \mathrm{Am}$ Optom Assoc 199263 411-417.

18. Wilkins AJ. Overlays for classroom and optometric use. Ophthal Physiol Opt 199414 97-99.
19. Evans BJW, Cook A, Richards IL, Drasdo N. Effect of pattern glare and coloured overlays on simulated reading task in dyslexic and normal readers. Optom Vis Sci 199471 619628.

20. Tyrell R, Holland K, Dennis D, Wilkins AJ. Coloured overlays, visual discomfort, visual search and classroom reading. J Res Reading 199518 10-23.

21. Wilkins AJ, Jeanes RJ, Pumfrey PD, Lakier M. Rate of Reading Test: its reliability, and its validity in the assessment of the effects of coloured overlays. Ophthal Physiol Opt 199616 491-497.

22. Jeanes RJ, Pumfrey PD, Laskier M. Speed of reading test: its reliability and its validity in the assessment of the effects of coloured overlays. Ophthal Physiol Opt 199616 491-497.

23. Wilkins AJ, Lewis E. Coloured overlays, text and texture. Percept 199928 642-650.

24. Wilkins AJ, Lewis E, Smith F. Rowland E. Coloured overlays and their benefits and their benefits for reading. $J$ Res Reading 2001181 10-23.

25. Bouldoukian J, Wilkins AJ, Evans BJW. Randomized controlled trial of the effect of coloured overlays on the rate of reading of people with specific learning difficulties. Ophthal Physiol Opt 200221 55-60.

26. Evans BJW, Joseph F. The effects of coloured filters on the rate of reading in adult student population. Ophthal Physiol Opt 200222 535-545.

27. Ludlouw A, Wilkins AJ, Heaton P. The effect of coloured overlays on reading ability in children with autism. $J A u$ tism Dev Disord 200636 507-516.

28. Smith L, Wilkins AJ. How many overlays are necessary to increase reading speed? A comparison of two systems. $J$ Res Reading 200730 332-343. 